\title{
Sperm competition and effects of mating order on copulatory behavior in meadow voles (Microtus pennsylvanicus)
}

\author{
DONALD A. DEWSBURY \\ University of Florida, Gainesville, Florida
}

\begin{abstract}
The pattern of sperm competition and effects of mating order were examined in meadow voles (Microtus pennsylvanicus). When males were the second to mate with a given female during an estrus, they had shorter latencies to intromission, longer latencies to ejaculation, longer mount durations, longer intromission durations, and higher mount frequencies and intromission frequencies than when mating first. Although few litters were produced, there was no suggestion of an order effect on litter composition.
\end{abstract}

Although animals generally copulate within a social context in nature, most laboratory studies of copulatory behavior have been conducted in single-pair situations. In the more natural situation, there are more complicated behavioral and physiological interactions that affect the reproductive success of individual males and females. A situation of sperm competition occurs when a female mates with more than one male during an estrous period. Given that two males mate with a single female, the pattern of sperm interaction and the resulting litter composition often differs across species, with first-male, last-male, and no differential advantages reported in different species (e.g., Dewsbury, 1984; Gwynne, 1984; Parker, 1970). It has been proposed that a last-male advantage may be most prevalent in species with substantial paternal investment, with the last-male advantage necessary for and related to confidence of paternity (see Gwynne). The pattern of sperm competition also varies within species according to prevailing conditions (e.g., Dewsbury, 1988b; Ginsberg \& Huck, 1989).

In addition, male copulatory behavior may be altered depending on the mating status of the female. Males of many rodent species display multiple intromissions prior to ejaculation. Several changes in the pattern of this behavior, the most reliable of which is an increase in the number of intromissions prior to ejaculation, may occur when males mate with recently mated, as opposed to unmated, females (e.g., Dewsbury, 1979, 1985). These changes are consistent with the proposal that one function of the multiple intromissions may be related to cleansing of the female reproductive tract of material from previous males, so that a given male may deposit sperm and a copulatory plug most effectively (Dewsbury, 1981).

The genus Microtus is an ideal group for comparative studies of reproductive behavior, because there is a vari-

This research was supported by Grant BNS-8904974 from the National Science Foundation. Correspondence should be addressed to D. A. Dewsbury, Department of Psychology, University of Florida, Gainesville, FL 32611-2065. ety of species with different mating systems and behavioral patterns. Meadow voles (Microtus pennsylvanicus) live most of the year in a social system with relatively little social interaction and are generally unlikely to form monogamous pairs (e.g., Madison, 1980a, 1980b; see also Madison \& McShea, 1987). This contrasts with other species in the genus, such as prairie voles (Microtus ochrogaster) (e.g., Getz \& Hofmann, 1986). These considerations would suggest that meadow voles might show no consistent order effects in a sperm-competition situation, because there is little consistent paternal investment in the care of their young (e.g., McGuire \& Novak, 1984). However, because multiple mating may be common in the field, behavioral modifications in response to the recent mating status of females may be prominent.

\section{METHOD}

\section{Subjects}

The subjects were 24 male and 28 female meadow voles (Microtus pennsylvanicus) from the colony maintained at the University of Florida. The mean age at the time of first test was 166 (96-245) days for males and $180(118-291)$ days for females. The animals were maintained in a windowless, air-conditioned room on a reversed 16:8-h light:dark photoperiod of white fluorescent light, with light offset at $1200 \mathrm{~h}$. The animals were housed in clear polycarbonate cages, measuring $48 \times 27 \times$ $13 \mathrm{~cm}$ for males and $29 \times 19 \times 13 \mathrm{~cm}$ for females. Wood shavings were provided as bedding, and water and Purina laboratory rodent chow and lettuce supplements were provided.

All the animals were known to be homozygous for one of the two alleles (slow or fast), affecting the rate of migration of transferrin (Trf) as determined by horizontal starch-gel electrophoresis (see Dewsbury, 1985). These will be referred to as " $S$ " and " $F$ " males and females.

All the animals had been pretested for fertility by pairing a male and a female and allowing them to produce a litter. The males were also pretested for copulatory behavior under experimental conditions by allowing them to copulate with a nonexperimental female in hormoneinduced estrus prior to serving in the experiment.

\section{Design}

The basic design called for estrous females to mate sequentially with 2 males, 1 of each Trf genotype, and to compare the behavior of the 2 males and analyze the composition of the resulting litters. Because the probability of pregnancy increases with increasing numbers of copulations (Gray, Kenney, \& Dewsbury, 1977), an effort was made to have 
the females mate for two ejaculations with each male. In both previous work and pilot testing, however, it became clear that it would be difficult to get the females to mate for two ejaculations with each of 2 males. Therefore, the females were permitted to mate for one ejaculation with each of 2 males. As will be seen, this led to a low incidence of pregnancy, so the animals had to be tested repeatedly in an effort to obtain litters. At the end of the study, as the males and females had become highly experienced, it was possible to complete a brief second experiment with the males mating for two ejaculations each. The females were retested as long as they failed to produce a litter. The males were retested, with attention to their serving as first and last male as equally as possible.

\section{Procedures}

In Experiment 1, the females were mated sequentially to 2 males, of differing $\mathrm{Trf}$ genotype, for one ejaculation each. Estrus was induced by pairing a male and female, across from each other and separated by a hardware cloth barrier for 3 days (see Gray et al., 1977). All tests were conducted in the colony room during the early part of the dark phase of the cycle. The tests were initiated by removing the barrier and permitting the male and female to copulate for one complete ejaculatory series. The female was then removed from the cage and placed into the cage of a second male, of the opposite Trf genotype, and permitted to copulate for one ejaculation. She was then returned to her home cage, together with a sample of bedding from the divided cage, and examined for the birth of a litter 21-24 days later. The procedure for Experiment 2 was identical to that of Experiment 1, except that the males were allowed to copulate for two ejaculations each.

\section{Measures}

Copulatory behavior in meadow voles consists of three primary classes of events: mounts (with no vaginal insertion), intromissions (mounts with vaginal insertion, generally with repetitive deep thrusting during the intromission), and ejaculations (with insertion and semen emission) (Gray \& Dewsbury, 1975). These events are organized into series, with each series beginning with an intromission and ending with an ejaculation. The following standard measures were used (see Gray \& Dewsbury, 1975): mount latency (ML), time (in seconds) from the start of a test until the first mount or intromission; intromission latency (IL), time (in seconds) from the start of a test until the first intromission; ejaculation latency (EL), time (in seconds) from the first intromission of a series until ejaculation; mount frequency (MF), the number of mounts in a series; intromission frequency (IF), the number of intromissions in a series; total mount duration (TMD), the total time (in seconds) spent in mounts within a series; total intromission duration (TID), the total time (in seconds) spent during intromissions within a series; ejaculation duration (ED), the duration (in seconds) of the ejaculatory response; total number of thrusts (TT), the number of deep thrusts in a series; ejaculatory thrusts (ET), the number of thrusts associated with an ejaculation; and mean interintromission interval (MIII), the mean interval (in seconds) separating the intromissions within a series.

\section{RESULTS}

In Experiment 1, a total of 156 tests were initiated, of which 50 went through to completion by having the females mate for one ejaculation with each of 2 males. Behavioral data were analyzed for the 16 males, $7 \mathrm{~F}$ and $9 \mathrm{~S}$, completing at least two tests in each of the two mating orders, first and second. Three-way analyses of variance, with genotype (F vs. S male between subjects), order (first vs. second), and test (first vs. second within an order) as main factors. There was only one significant effect of repeated testing: IF was significantly higher in the second of the two tests within condition $[M=21.0 \mathrm{vs}$. 15.4, $F(1,14)=5.42, p<.033]$. Few interactions were statistically significant. Data for effects of genotype and order on copulatory behavior are presented in Table 1. There were three effects of genotype, with $\mathrm{S}$ males having longer ELs and higher MFs and IFs. Mating order had a significant effect on five measures. The males had shorter ILs, longer ELs, TMDs, and TIDs, and higher MFs and IFs when mating last than when mating first.

A total of 19 tests were attempted in Experiment 2, with 8 reaching completion. Behavioral data were not amenable to statistical analysis.

Litters were delivered after only 7 of the 50 completed tests in Experiment 1. Genotypes were determined for 29 pups from the seven litters. There was no significant effect of mating order; first males sired 14 pups and last males sired 15. The mean interval from the first male's ejaculation to the second male's first intromission was $329 \mathrm{sec}$ (range $=134-577$ ). Only one litter was delivered in Experiment 2, and only 1 pup from that litter could be typed; it was sired by the last male.

\section{DISCUSSION}

The most obvious result of this work was a reinforcement of laboratory lore concerning the difficulty of working with this species compared with congeneric species such as prairie voles (Microtus ochrogaster) and montane voles (Microtus montanus) (see Dewsbury, 1988a, 1990). Both the induction of estrus in females and the initiation of copulation by males were problematic, yielding a success rate for complete mating by both males of just $32 \%$ and for litter production of just $4 \%$ of the tests initi-

Table 1

Measures of Copulatory Behavior in Meadow Voles as a Function of Genotype and Order of Mating

\begin{tabular}{|c|c|c|c|c|c|c|}
\hline \multirow[b]{3}{*}{ Measure } & \multicolumn{3}{|c|}{ Genotype } & \multicolumn{3}{|c|}{ Order } \\
\hline & $M$ & $M$ & & $M$ & $M$ & \\
\hline & $\overline{\text { F Male }}$ & $\overline{S \text { Male }}$ & $F(1,14)$ & $\overline{\text { Male } 1}$ & $\overline{\text { Male } 2}$ & $F(1,14)$ \\
\hline ML* & 151.9 & 225.2 & 0.65 & 272.4 & 134.5 & 2.95 \\
\hline $\mathrm{IL}^{*}$ & 220.1 & 279.3 & 0.39 & 357.5 & 147.6 & $5.06 \dagger$ \\
\hline EL* & 432.7 & 762.3 & $5.61 \dagger$ & 487.4 & 748.8 & $9.24 \ddagger$ \\
\hline MF & 7.0 & 15.2 & $6.65 \dagger$ & 8.4 & 16.9 & $6.21 \dagger$ \\
\hline IF & 12.4 & 22.7 & $7.00 \dagger$ & 13.5 & 22.9 & $8.58 \dagger$ \\
\hline TMD* & 12.4 & 23.2 & 4.32 & 10.5 & 26.4 & $12.29 \ddagger$ \\
\hline TID* & 48.9 & 61.6 & 1.43 & 47.1 & 64.1 & $6.37 \dagger$ \\
\hline ED* & 3.9 & 4.1 & 0.18 & 4.2 & 3.8 & 0.84 \\
\hline TT & 45.6 & 60.7 & 3.96 & 47.2 & 61.0 & 4.11 \\
\hline ET & 8.9 & 7.4 & 2.35 & 8.1 & 8.1 & 0.00 \\
\hline MIII* & 42.3 & 41.2 & 0.01 & 46.5 & 36.9 & 0.74 \\
\hline
\end{tabular}

Note-See text for definitions of measures. *In seconds. $\dagger p<.05$. $\ddagger p<.01$. 
ated. The problem was not substantially helped by permitting the males to deliver two ejaculations each, rather than one. It is possible that, like deer mice (Dewsbury, 1982), meadow voles display a pericopulatory pregnancy block, with a lower probability of pregnancy after mating with two males than with one. This possibility merits systematic investigation.

An important concern in studies of sperm competition is that the marker gene used to differentiate the genotypes of males be neutral with respect to behavior and reproductive success; this is not always the case (e.g., Lanier, Estep, \& Dewsbury, 1979). These may be real differences, but they do not appear to be of sufficient magnitude to compromise the use of the marker in studies of sperm competition.

The most important behavioral observation in this study was the effect of mating order on copulatory behavior. When mating last, the males had significantly longer ILs, ELs, TMDs, and TIDs, and higher MFs and IFs. There is some cross-species consistency of effects of mating order on male copulatory behavior. It has generally been found that when mating with recently mated females, male deer mice also tend to have shorter MLs and ILs, longer ELs, and higher IFs and MFs than when mating with unmated females (Dewsbury, 1979, 1985; Dewsbury \& Baumgardner, 1981). Male prairie voles tend to have higher MFs when mating with recently mated females (see Dewsbury \& Baumgardner). These changes may reflect changes in female resistance to mating. At the beginning of a test, females often display some resistance to mating, which decreases once copulation is initiated; typically, resistance also increases near the ends of sessions. When males mate with previously mated females, they appear to be able to bypass this initial phase of resistance, but encounter the increased resistance that is typical late in testing.

Alternatively, these changes in behavior may be viewed as adaptations on the part of males. If males are to initiate pregnancy in the female effectively, the ejaculate must be lodged properly in the female's reproductive tract (Matthews \& Adler, 1977, 1978, 1979). An important function of pre-ejaculatory intromissions may be the cleansing of the tract of accumulated material so that the ejaculate can be properly placed (Dewsbury, 1981). Females that have not mated recently may have vaginal casts in their tracts. However, females that have mated with another male will have more material in the tract. The increase in number of intromissions may be related to the removal of that material when mating with a previously mated female.

The sample size for analysis of order effects in sperm competition is distressingly small, despite substantial efforts to generate data. Nevertheless, there is no suggestion of an order effect on sperm competition. This agrees with Gwynne's (1984) argument relating to paternal investment, certainty of paternity, and sperm competition. Last-male advantages should be most common in species with substantial paternal investment; this pattern is not shown by meadow voles (McGuire \& Novak, 1984). In this respect, meadow voles are similar to both laboratory rats (Lanier et al., 1979) and deer mice (e.g., Dewsbury \& Baumgardner, 1981).

However, some caution may be necessary in interpreting such data in relation to mating systems. Increasingly in recent years the pattern of interaction of the sperm from two males has been found to vary with prevailing conditions (e.g., Bryan, 1989; Dewsbury, 1988b; Huck, Seger, \& Lisk, 1990). It now seems naive to expect a single, "speciestypical" pattern in sperm competition. It remains to be seen whether a single set of parameters can be found that will enable meaningful crossspecies comparisons and permit an evaluation of the hypothesis relating sperm-competition patterns to paternal effort and certainty.

\section{REFERENCES}

BRYAN, J. C. (1989). Effects of mating order and time between males on sperm competition in prairie voles, Microtus ochrogaster. Unpublished master's thesis, University of Florida, Gainesville.

Dewsbury, D. A. (1979). Copulatory behavior of deer mice (Peromyscus maniculatus): II. A study of some factors regulating the fine structure of behavior. Journal of Comparative \& Physiological Psychology, 93, 178-188.

DEWSBURY, D. A. (1981). On the function of the multiple-intromission multiple-ejaculation copulatory patterns of rodents. Bulletin of the Psychonomic Society, 18, 221-223.

DewSBURY, D. A. (1982). Pregnancy blockage following multiple-male copulation at the time of mating in deer mice, Peromyscus maniculatus. Behavioral Ecology \& Sociobiology, 11, 37-42.

DewsBury, D. A. (1984). Sperm competition in muroid rodents. In R. L. Smith (Ed.), Sperm competition and the evolution of animal mating systems (pp. 547-571). New York: Academic Press.

DewSBuRY, D. A. (1985). Studies of the effects of variation at the transferrin locus on reproductive processes in deer mice (Peromyscus maniculatus). Acta Theriologica, 30, 227-240.

DEWSBURY, D. A. (1988a). The comparative psychology of monogamy. Nebraska Symposium on Motivation, 35, 1-50.

Dewsbury, D. A. (1988b). Sperm competition in deer mice (Peromyscus maniculatus bairdi): Effects of cycling versus postpartum estrus and delays between matings. Behavioral Ecology \& Sociobiology, 22, 251-256.

DEWSBURY, D. A. (1990). Individual attributes generating contrasting degrees of sociality in voles. In R. H. Tamarin, R. S. Ostfeld, S. R. Pugh, \& G. Bujalska (Eds.), Social systems and population cycles in voles (pp. 1-9). Basel: Birkhauser Verlag.

Dewsbury, D. A., \& BAumgardner, D. J. (1981). Studies of sperm competition in two species of muroid rodents. Behavioral Ecology \& Sociobiology, 9, 121-133.

Getz, L. L., \& Hofmann, J. E. (1986). Social organization in freeliving prairie voles, Microtus ochrogaster. Behavioral Ecology \& Sociobiology, 18, 275-282.

GinsBerG, J. R., \& HuCK, U. W. (1989). Sperm competition in mammals. Trends in Ecology \& Evolution, 4, 74-79.

Gray, G. D., \& DewsbURY, D. A. (1975). A quantitative description of the copulatory behavior of meadow voles (Microtus pennsylvanicus). Animal Behaviour, 23, 261-267.

Gray, G. D., Kenney, A. M., \& Dewsbury, D. A. (1977). Adaptive significance of the copulatory pattern of male meadow voles (Microtus pennsylvanicus) in relation to the induction of ovulation and implantation in females. Journal of Comparative \& Physiological Psychology, 91, 1308-1319.

GWYNNE, D. T. (1984). Male mating effort, confidence of paternity, and insect sperm competition. In R. L. Smith (Ed.), Sperm competition and the evolution of animal mating systems (pp. 547-571). New York: Academic Press.

HuCK, U. W., Seger, J., Lisk, R. D. (1990). Litter sex ratios in the golden hamster vary with time of mating and litter size and are not bimodally distributed. Behavioral Ecology \& Sociobiology, 26, 99-109.

LAnier, D. L., Estep, D. Q., \& Dewsbury, D. A. (1979). The role of prolonged copulatory behavior in facilitating reproductive success in a mating situation in laboratory rats. Journal of Comparative \& Physiological Psychology, 93, 781-792.

MADISON, D. M. (1980a). An integrated view of the social biology of Microtus pennsylvanicus. Biologist, 62, 20-33.

Madison, D. M. (1980b). Space use and social structure in meadow voles, Microtus pennsylvanicus. Behavioral Ecology \& Sociobiology, 7, 65-71.

Madison, D. M., \& McShea, W. J. (1987). Seasonal changes in reproductive tolerance, spacing, and social organization in meadow voles: A microtine model. American Zoologist, 27, 899-908.

Matthews, M. K., \& Adler, N. T. (1977). Facilitative and inhibitory influences of reproductive behavior on sperm transport in rats. Journal of Comparative \& Physiological Psychology, 91, 727-741.

Matthews, M. K., \& ADLER, N. T. (1978). Systematic interrelationship of mating, vaginal plug position, and sperm transport in the rat. Physiology \& Behavior, 20, 303-309.

Matthews, M. K., \& Adler, N. T. (1979). Relative efficiency of sperm transport and number of sperm ejaculated in the female rat. Biology of Reproduction, 20, 540-544.

McGuire, B., \& Novak, M. (1984). A comparison of maternal behaviour in the meadow vole (Microtus pennsylvanicus), prairie vole (M. ochrogaster) and pine vole (M. pinetorum). Animal Behaviour, 32, 1132-1141.

PARKer, G. A. (1970). Sperm competition and its evolutionary consequences in the insects. Biological Reviews, 45, 525-567.

(Manuscript received May 5, 1993.) 